Research Article

\title{
Grouting Reinforcement Technique in Wind Oxidation Zone by Power Law Superfine Cement Slurry Considering the Time-Varying Rheological Parameters
}

\author{
Dengxing Zhu ${ }^{D},{ }^{1}$ Yu Guo ${ }^{D},{ }^{2}$ Wei Wang, ${ }^{2}$ Gangye Guo, ${ }^{3}$ and Tieliang An ${ }^{1}$ \\ ${ }^{1}$ Key Laboratory of Deep Coal Resource Mining, Ministry of Education, China University of Mining and Technology, \\ Xuzhou, Jiangsu 221116, China \\ ${ }^{2}$ Jiangsu Vocational Institute of Architectural Technology, Xuzhou, Jiangsu 221116, China \\ ${ }^{3}$ Coal Mining and Designing Department, Tiandi Science and Technology Co., Ltd., Beijing 100013, China \\ Correspondence should be addressed to Yu Guo; hnnygy@126.com
}

Received 25 February 2019; Revised 23 June 2019; Accepted 7 September 2019; Published 19 November 2019

Academic Editor: Arnaud Perrot

Copyright (C) 2019 Dengxing Zhu et al. This is an open access article distributed under the Creative Commons Attribution License, which permits unrestricted use, distribution, and reproduction in any medium, provided the original work is properly cited.

\begin{abstract}
With the recovery of the wind oxidation zone in 13116 working face of Gubei Coal Mine as the engineering background, the occurrence condition of coal seam and the bedrock wind oxidation zone characteristics were analyzed. On this basis, the time-varying rheological parameters of superfine cement slurry and the permeability characteristic parameters of roof strata in wind oxidation zone were measured; then, a grout diffusion equation was established with the parameters obtained previously for the permeability characteristics of roof strata in the wind oxidation zone of Gubei Coal Mine. The grouting design was applied in actual engineering projects and its engineering effect has been proved to be satisfactory. The results indicate that superfine cement slurry whose watercement ratio is 0.6 is a typical power-law slurry consistent with time-varying rheological parameters. It has better rheological properties during pumpable period, and its rheological parameters can be controlled by highly dispersive nano- $\mathrm{SiO}_{2}$ and polycarboxylate superplasticizer. For grouting in wind oxidized zone, comprehensive consideration must be given to effective permeability $K_{\mathrm{e}}$, porosity $\varnothing$, and time-varying rheological parameters $c_{0}, k$, and $n$. To realize effective diffusion of grouting in coal and rock mass, grouting pressure and diffusion time must be reasonably designed rather than excessively increased.
\end{abstract}

\section{Introduction}

Under the joint impact of sedimentary water and weathered damage, the coal roof in wind oxidation zone becomes hard to manage due to the rise in porosity and the consequent fall in strength and bearing capacity. To mine in wind oxidation zone, water flowing fracture zone and caving zone may easily spread over upper aquifer, which triggers water and sand inrush and causes production accidents in the end.

In view of the characteristics of strata weathered damage and mine pressure behavior of wind oxidation zone, pregrouting reinforcement of coal roof is a key technology to solve the problems associated with mining in wind oxidation zone. A great number of researches on grouting reinforcement in wind oxidation zone have been conducted by domestic experts and engineering technicians. Tu et al. and Zhang et al. [1,2] put forward that J-type horizontal wing branch pore grouting method could be used to reinforce wind oxidation zone, which could improve the integral strength and bearing capacity of bedrock strata effectively. Besides, the roof weighting step of working face is also larger than that of ungrouted working face. Peng et al. [3] analyzed the mechanism of end-face roof fall in wind oxidation zone of Jing Gong III fully mechanized caving face in Ping Shuo Coal Mine and put forward some actual measures against end-face roof fall and specifications for the thickness of endface roof reinforcement. Zhang [4] studied the movement law of overlying strata before and after grouting reinforcement in thick loose wind oxidation zone and measured the working resistance of support after grouting. On 
this basis, he demonstrated the adaptability of hydraulic support. Ma [5] analyzed the stability of roof and floor in the process of mining in wind oxidation zone by using UDEC software and determined the grouting reinforcement thickness of roof and floor. According to the characteristics of wind oxidation zone in 39017 working face of Gong III shaft in Pingshuo Coal Mine, Yang and Shi [6] put forward many feasible measures to control surrounding rock, like advanced grouting reinforcement in assistant haulage roadway, grouting before working face support, improving setting load of support, and mesh placement on top beam. All these measures were proved to be economically beneficial. Tian and Shi [7] developed a testing system for highpressure sealing grouting to study the seepage and pore permeability law of chemical grout in the grouted medium. Then, they improved the grouting parameters of wind oxidation zone of Jing Gong III fully mechanized caving face in Ping Shuo Coal Mine, which saved up to $56 \%$ of grouting material for the grouting project.

From the above researches, it can be observed that the current roof grouting practice in wind oxidation zone relies more on engineering experience than on grouting diffusion model established by known geological parameters, slurry performance index, and field working parameters to depict the law of slurry movement and predict the diffusion range of slurry in wind oxidation zone. However, this grouting practice is blind to some degree [8]. On the other hand, currently, quick-setting grouting materials are used for grouting reinforcement in wind oxidation zone. In this case, the slurry viscosity increases too fast, and consequently, the shear rate and stress do not follow a simple linear relationship. The slurry becomes in essence a non-Newtonian fluid whose rheological parameters are in the process of dynamic change and thus become a crucial factor for grouting pressure and diffusion radius in the process of grouting $[9,10]$.

With the recovery of the wind oxidation zone in 13116 working face of Gubei Coal Mine as the engineering background, this study analyzed the occurrence condition of coal seam, the distribution characteristics of upper aquifer and aquiclude, and the bedrock wind oxidation zone characteristics. On this basis, the time-varying rheological parameters of superfine cement slurry and the permeability characteristic parameters of roof strata in wind oxidation zone were measured. By way of the parameters obtained, a relation equation of grouting pressure and diffusion distance under different grouting and diffusion time was deduced. The grouting design for the project under study was optimized according to the results obtained, and its engineering effect has been proved to be satisfactory, which provides reference and instruction for grouting reinforcement under similar geological conditions.

\section{Mining Conditions and Rock Features}

2.1. Occurrence Conditions of Coal Seam. The 13116 working face is $170 \mathrm{~m}$ wide, with a regular coal seam whose average thickness is $3.4 \mathrm{~m}$. The thickness of coal seam varies southward greatly from $2.1 \mathrm{~m}$ to $5.5 \mathrm{~m}$ (near the open-off cut). The obliquity of coal seam ranges from $3^{\circ}$ to $12^{\circ}$, with an average of $7^{\circ}$. The $6-2$ coal whose unit weight is $1.4 \mathrm{t} / \mathrm{m}^{3}$ is composed of mainly durain, and secondly, clarain and vitrain. The coal is mainly power like with few small lumps.

The immediate roof of 13116 working face is a compound roof composed of mudstone and coal streaks. It is about $0.9 \sim 6.1 \mathrm{~m}$ thick, with an average thickness of $4.0 \mathrm{~m}$. There are one or two coal streaks which develop unstably with a thickness of $0 \sim 0.6 \mathrm{~m}$. The main roof is fine siltstone which is $1.8 \sim 7.6 \mathrm{~m}$ thick with an average thickness of $3.5 \mathrm{~m}$. The immediate floor is composed of mudstone and coal streaks with an average thickness of $1.4 \mathrm{~m}$. The bottom layer of immediate floor is a $0.4 \mathrm{~m}$ thick, irregular coal streak. The main floor is fine siltstone with an average thickness of $9.4 \mathrm{~m}$. The comprehensive geological conditions of coal seam roof and floor are shown in Figure 1.

2.2. The Distribution Law of Three Aquicludes and Rock Features. The coal measure strata are covered by a $440 \sim 468 \mathrm{~m}$ thick layer of loose sediments, which developed into three aquifers and three aquicludes. Below the lower aquiclude is the bottom "red bed" composed of yellow clay mingled with gray conglomerate. The characteristics of every layer are shown in Table 1. Among all the geological layers, the lower aquiclude and the bottom "red bed" are the most influential to the mining in this working face. The lower aquiclude, with a stable distribution, is mainly composed of gray and brown clay and sandy clay, and it has excellent waterproof performance; the bottom "red bed" demonstrates a poor water yield property when drilled through, but its distribution is not stable. The water mining level of this working face is Level II, which means that water flowing fracture zone is permitted to spread to the water in loose aquifer, but caving zone is not.

\subsection{Characteristics of Wind Oxidation Zone in the Bedrock.} The wind oxidation zone of 13116 working face is a triangular area whose three vertexes are the open-off cut, the point $165 \mathrm{~m}$ inward from the entrance of belt haulage roadway, and the point $82 \mathrm{~m}$ toward the open-off cut from the entrance of belt haulage roadway. The wind oxidization zone is $16.0 \sim 33.0 \mathrm{~m}$ thick, with an average thickness of $24.5 \mathrm{~m}$. The lithology is mainly medium and fine sandstone, sandy mudstone, and mudstone, which is earthy yellow and partially purple, light gray, or dark yellow. The water storage capacity of weathered sandstone fracture depends on its water-conducting property and the development of microfractures. The resource exploration and supplement exploration show that no water leakage occurs when the wind oxidation zone is drilled through, indicating that it can obstruct effectively the water permeation from cenozoic loose aquifer to the bedrock.

After the excavation of the open-off cut and belt haulage roadway of 13116 working face, some bolts and cables in the roof and sidewalls broke, and local roof mesh ruptured, which led to roof leakage and the disability of some canopy point pillars. According to the above analysis of occurrence 


\begin{tabular}{|c|c|c|c|}
\hline Roof and floor & Histogram & Thickness & Name of the rock seam \\
\hline Main roof & 3.0 & Sandy mudstone \\
\hline Immediate roof & 3.5 & Middle-fine sandstone \\
\hline Coal seam & 0.6 & Coal \\
\hline Immediate floor & 1.7 & Mudstone \\
\hline Main floor & 0.5 & Coal seam \\
\hline & 1.2 & Mudstone \\
\hline & 0.4 & 6-2 coal seam \\
\hline
\end{tabular}

FIgURE 1: Comprehensive geological histogram of coal seams.

TABLE 1: Characteristics of loose sediments in the mine.

\begin{tabular}{|c|c|c|c|c|c|}
\hline Rock stratum & Bottom boundary depth (m) & Thickness (m) & Hydrological parameters & Lithology & Watery \\
\hline Central aquifer & $369.70 \sim 378.40$ & $34.70 \sim 70.60$ & $\begin{array}{l}Q=5.747 \\
q=0.504 \\
h=19.16\end{array}$ & Sand and clay & Medium \\
\hline Central aquiclude & $404.40 \sim 441.20$ & $39.25 \sim 64.00$ & $\begin{array}{l}q=0.0019 \\
Q=5.747\end{array}$ & Sandy clay & Poor \\
\hline Lower aquifer & & $0 \sim 3.50$ & $\begin{array}{c}q=0.00485 \\
h=10.228\end{array}$ & Sandy clay & Poor \\
\hline Lower aquiclude & $440.55 \sim 461.35$ & $0 \sim 46.10$ & & Calcareous clay & Poor \\
\hline Bottom "red bed" & & $0 \sim 3.65$ & $q=0.0016$ & Yellow clay & Poor \\
\hline
\end{tabular}

Note: $h$ denotes the elevation of static water level in $m$; $Q$ refers to the water consumption in $\mathrm{L} / \mathrm{s} ; q$ is the water consumption in $\mathrm{L} /(\mathrm{s} \cdot \mathrm{m})$.

conditions of coal seam, bedrock, and waterproof characteristics of the aquifer in wind oxidation zone, it is necessary to conduct grouting reinforcement to the open-off cut and the roof of wind oxidation zone in belt haulage roadway to avoid water inrush or support crushing accidents in the process of mining.

\section{The Law of Permeation and Diffusion of Power-Law Superfine Cement Slurry}

3.1. Cylindrical Permeation and Diffusion Law of Superfine Cement Slurry. Controlling the rheological property of slurry is one of the key points of grouting technology. Only when the rheological property of slurry is reasonable, it can be effectively injected into the microcracks of coal and rock mass. Therefore, a large number of scholars have studied the rheological property of cement slurry [11-20]. Compared with common cement slurry, superfine cement slurry possesses a much better reinforcement and seepage-proofing performance in its particles that are tiny enough to be grouted into the micropore space in the rock of wind oxidation zone. As the particle size decreases, the slurry viscosity increases, and the slurry with high-performance polymer water reducer is pseudoplastic fluid. Cement slurry is considered as Ostwald fluid, or generally, it presents a Herschel-Buckley behavior with the presence of yield stress. In the case of superfine cement slurry, the yield stress is lower, so it is considered as Ostwald fluid, and its basic rheological equation can be shown as follows [21]:

$$
\tau=c \gamma^{n}
$$

where $\tau$ denotes shear stress; $c$ denotes coefficient of viscosity; $\gamma$ refers to shear rate and $\gamma=-\mathrm{d} v / \mathrm{d} t$; and $n$ denotes rheological index, a nondimensional indication of the nonNewtonian fluid behavior of the material.

According to the studies conducted by Ruan et al. [8, 22-24], the rheological equation of time-varying superfine cement slurry with rheological parameters can be displayed as follows:

$$
\tau=c t \gamma^{n}=c_{0} e^{k t} \gamma^{n}
$$

where $c_{0}$ denotes the initial coefficient of viscosity; $c(t)$ refers to the coefficient of viscosity at the moment of $t$; and $k$ is time-varying coefficient of viscosity.

According to the study of Yang et al. [25], the grouting diffusion mechanism of time-varying, power-law, superfine, 
cement slurry, cylindrical model with rheological parameters can be shown by the following equation:

$$
p-p_{0}=\frac{e^{t}}{1-2 n}\left(\frac{\mu_{\mathrm{e}}}{K_{\mathrm{e}}}\right)\left(\frac{\varnothing}{2 t}\right)^{n}\left(R^{1-n}-R_{0}^{1-n}\right) R^{2 n}
$$

where $p$ denotes grouting pressure, $p_{0}$ is the hydraulic pressure of grouting point; $R$ refers to grouting diffusion radius; $\mu_{\mathrm{e}}$ denotes effective viscosity; $K_{\mathrm{e}}$ refers to effective permeability; $\varnothing$ is the porosity of grouted medium; $t$ represents the grouting time; $R_{0}$ stands for the radius of grouting pipe; and $n$ refers to rheological index. In addition, $\mu_{\mathrm{e}}$ and $K_{\mathrm{e}}$ can be calculated by the following equations:

$$
\begin{aligned}
& \mu_{\mathrm{e}}=c_{0}\left(\frac{1+3 n}{\varnothing R_{0} n}\right)^{n-1}, \\
& K_{\mathrm{e}}=\frac{\varnothing R_{0}^{2}}{2}\left(\frac{n}{3 n+1}\right), \\
& \varnothing=\frac{\gamma_{\mathrm{s}}(1+w)-\gamma_{\mathrm{r}}}{\gamma_{\mathrm{s}}(1+w)},
\end{aligned}
$$

where $c_{0}$ refers to the initial viscosity efficient; $\gamma_{\mathrm{r}}$ denotes natural gravity of grouted rock sample; $\gamma_{\mathrm{s}}$ represents particle density of grouted rock; and $w$ denotes water cut of grouted rock.

By substituting equations (4)-(6) into equation (3), the relation of $p$ and $R$ with $p_{0}, k, n, c_{0}, R_{0}, \gamma_{\mathrm{s}}, w, \gamma$, and $t$ can be obtained. $p_{0}$ can be measured through field test; $k, n$, and $c_{0}$ are determined by the rheological characteristics of superfine cement grout and thus can be obtained through field measurement; meanwhile, they can be controlled by adjusting the amount of additive of superfine cement grout. $\gamma_{\mathrm{s}}, w$, and $\gamma_{\mathrm{r}}$ are determined by the permeability of grouted rock and thus can be obtained through measuring the rock sample extracted from the grouting point according to the related national standard [26].

\subsection{The Rheological Behavior of Superfine Cement Grout}

3.2.1. Superfine Cement Material. The cement used in the test is common P.O42.5 cement produced by China United Cement Xuzhou Co., Ltd. After grinding and screening with ball mills, the common P.O42.5 cement can be used as superfine cement material. The size of $95 \%$ particles is below $20 \mu \mathrm{m}$, and its specific surface area is $1.8939 \mathrm{~m}^{2} / \mathrm{g}$. The actual chemical composition is shown in Table 2.

\subsubsection{The Measurement of Rheological Behavior of Superfine} Cement Grout. Two rheometers (LV and HB of DV3T series) manufactured by American Brookfield Company were used, and two rotors (SC4-21 and LV3-1) were chosen to measure the actual rheological behavior of superfine cement grout. Superfine cement grout was tested to measure its shear stress at different shear rates and time-varying viscosity (Figure 2) [27]. The water to cement ratio was set at 0.6; self-developed highly dispersive nano- $\mathrm{SiO}_{2}$ and polycarboxylate superplasticizer were added to the superfine cement grout used in the test as additives; a German IKA
TABLE 2: Chemical composition of superfine cement grout.

\begin{tabular}{lccccccc}
\hline $\mathrm{SiO}_{2}$ & $\mathrm{Al}_{2} \mathrm{O}_{3}$ & $\mathrm{Fe}_{2} \mathrm{O}_{3}$ & $\mathrm{CaO}$ & $\mathrm{MgO}$ & $\mathrm{SO}_{3}$ & $\mathrm{TiO}_{2}$ & Loss \\
\hline 19.96 & 5.68 & 2.62 & 58.99 & 2.64 & 2.78 & 0.27 & 5.08 \\
\hline
\end{tabular}

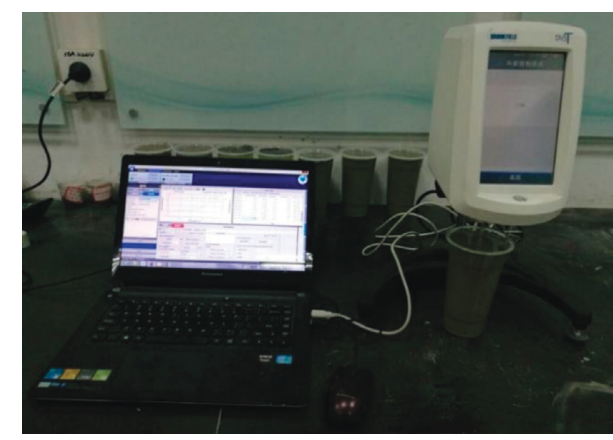

Figure 2: DV3T rheometer.

RW20 digital electric cantilever mixer was used to mix the grout. The grout was mixed at a rotational speed of more than $1800 \mathrm{rpm}$ for at least $3 \mathrm{~min}$ to ensure the even diffusion of additives in superfine cement grout. Cement grouts with different amounts of additive $(0,1 \%, 3 \%$, and $5 \%$ of the total) were produced for following tests.

Figure 3 shows the viscosity-time curve of superfine cement slurry with different additive amounts $(0,1 \%, 3 \%$, and $5 \%$ of the total). As is shown, the viscosity does not change much during the first $25 \mathrm{~min}$; then, it experiences a sharp increase. The larger the amount of additive is, the greater the viscosity becomes. Based on the data obtained, a viscosity time-varying equation of super cement grout can be fitted with Origin software (as shown in Table 3).

Figure 4 shows the rheological curves of superfine cement grouts with different additive amounts $(0,1 \%, 3 \%$, and $5 \%)$. As is indicated, when the amount of additive is relatively small, the rheological curve is similar. As the amount of nanoadditive increases, the shear stress increases correspondingly to the rising shear rate. However, the flow pattern of nanoadditive remains unchanged, which is in line with the characteristics of power-law fluids. In the actual construction of superfine cement grouting, grouting pressure is generally relatively large, and slurry flow is rarely in the low shear rate region, so this article does not consider the case of slurry rheological curve in low shear rate region. Based on the data obtained, a rheological equation of superfine cement grout can be fitted with Origin software (as shown in Table 3).

Pumpable time refers to a period before cement slurry can be pumped, which is also called "thickening time" in some countries. It is generally believed that the longest time for the pumped superfine cement slurry to maintain its fluidity of $150 \mathrm{~mm}$ is the pumpable time from the time when the slurry is mixed with water [28-30]. A frustum $(\Phi 40 * 60 * 60 \mathrm{~mm}$ ) was used to test the fluidity of superfine cement grouts with different additive amounts on plain glass plates conforming to the Chinese National Standard GB/ T8077-2012 [31], thus determining the pumpable time of each grout (as shown in Table 3). As can be seen, the pumpable time of grouts is below $30 \mathrm{~min}$. 


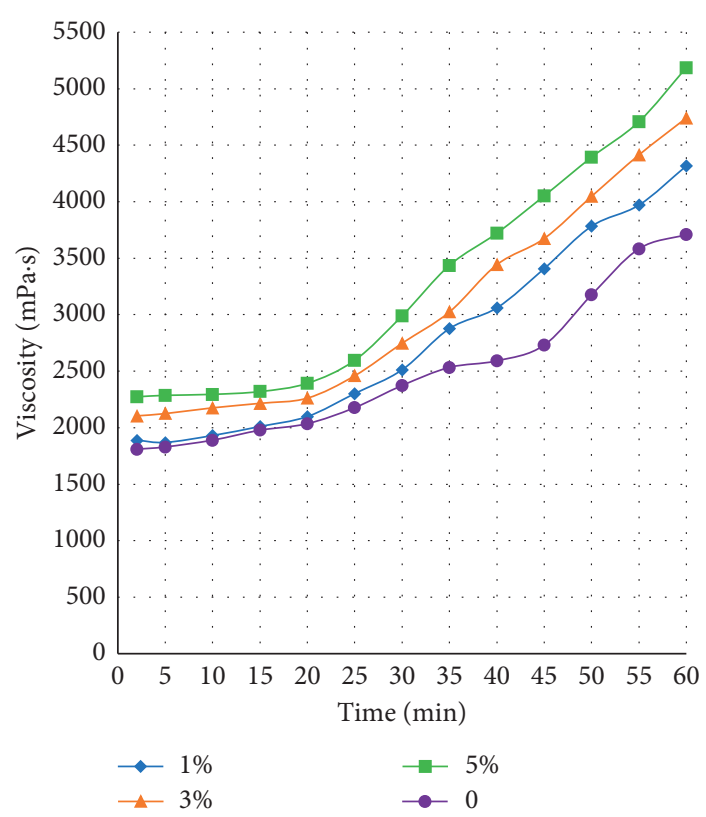

FIGURE 3: Viscosity-time curves of superfine cement slurry with different additive amounts.

TABLE 3: Effect of different additive amounts on rheological properties of superfine cement slurry.

\begin{tabular}{lccccc}
\hline Additive amount & Viscosity time-varying equation & $R^{2}$ & Rheological equation & $R^{2}$ & Pumpable time (min) \\
\hline 0 & $y=1644.3 e^{0.0127 x}$ & 0.9566 & $y=0.5787 x^{0.5121}$ & 0.9778 & 29 \\
$1 \%$ & $y=1692.1 e^{0.0154 x}$ & 0.9865 & $y=0.609 x^{0.5195}$ & 0.9852 & 29 \\
$3 \%$ & $y=1960.7 e^{0.014 x}$ & 0.9647 & $y=1.6087 x^{0.3632}$ & 0.9837 & 28 \\
$5 \%$ & $y=2115.1 e^{0.0145 x}$ & 0.9949 & $y=1.9195 x^{0.4093}$ & 0.9891 & 26.5 \\
\hline
\end{tabular}

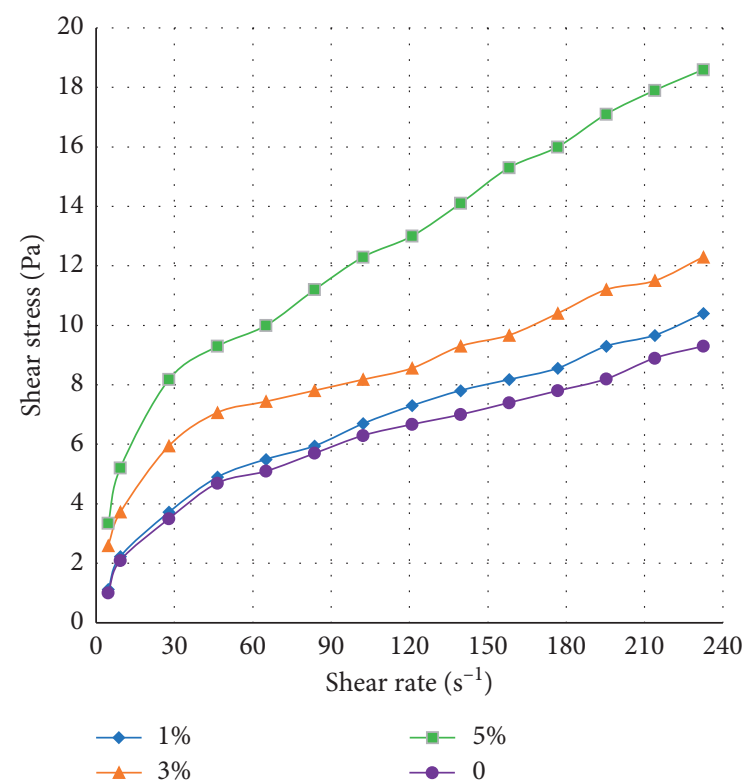

Figure 4: Rheological curves of superfine cement slurry with different additive amounts.

In addition, the mixed additive of nano- $\mathrm{SiO}_{2}$ and polycarboxylate superplasticizer was added to water. The superfine cement grouts with different amounts of additive were made into standard samples $(100 \mathrm{~mm} \times 100 \mathrm{~mm} \times 100 \mathrm{~mm})$ that were then maintained under standard maintenance environment. The sample strength data of different ages could be obtained. According to the data obtained, when the amount of additive reaches $3 \%$, the sample displays a relatively high strength. Therefore, the rheological parameters in this case were taken as grouting design parameters: $k=0.0014$, $n=0.3632$, and $c_{0}=1692.1 \mathrm{MPa} \cdot \mathrm{s}$. When $n$ is smaller than 1 , the superfine cement grout is pseudoplastic fluid whose apparent viscosity decreases as shear rate increases. Its high thixotropy is beneficial to the diffusion of grouting throughout the pores.

\subsection{The Rock Permeability Measurement of Wind Oxidation} Zone. Rock samples of wind oxidation zone of Gubei Coal Mine were obtained through drilling. According to "Standard for Soil Test Method" (GB/T50123-1999), the density of rock samples were measured and then conversed to weightspecific density $\gamma_{\mathrm{s}}$. Similarly, the particle unit weight $\gamma_{\mathrm{r}}$ and water cut $w$ were measured. According to the equipment available in the Gubei Coal Mine, it can be known that the radius of grouting pipe $R_{0}$ is $13 \mathrm{~mm}$. The values of $R_{0}, \gamma_{\mathrm{s}}, \gamma_{\mathrm{r}}$, and $w$ were substituted into equations (4)-(6) to calculate the value of effective viscosity $\mu_{\mathrm{e}}$, effective permeability $K_{\mathrm{e}}$, and porosity of grouted medium $\varnothing$. The values obtained are shown in Table 4. 
TABLE 4: Grouting parameters.

\begin{tabular}{ccccccccccc}
\hline$k$ & $n$ & $c_{0}\left(\mathrm{~Pa} \cdot \mathrm{s}^{n}\right)$ & $R_{0}(\mathrm{~mm})$ & $\gamma_{\mathrm{s}}\left(\mathrm{kN} / \mathrm{m}^{3}\right)$ & $w(\%)$ & $\gamma_{\mathrm{r}}\left(\mathrm{kN} / \mathrm{m}^{3}\right)$ & $\varnothing(\%)$ & $\mu_{\mathrm{e}}(\mathrm{MPa} \cdot \mathrm{s})$ & $K_{\mathrm{e}}(\mathrm{m} / \mathrm{s})$ & $P_{0}(\mathrm{MPa})$ \\
\hline 0.014 & 0.3632 & 1.96 & 13 & 25.2 & 3 & 22.6 & 12.9 & 91.32 & $1.89 \times 10^{-6}$ & 0.3 \\
\hline
\end{tabular}

3.4. The Diffusion Equation of Superfine Cement Grout in Wind Oxidation Zone. The data in Table 4 were substituted into equation (3), and then, the relation equation of grouting pressure and diffusion distance at different time $t$ in wind oxidation zone of Gubei Coal Mine can be obtained and shown as follows:

$$
p=48.99 \frac{e^{0.014 t}}{t^{0.3632}}\left(R^{1.3632}-0.0629 R^{0.7264}\right)+0.3
$$

The relation curves of grouting pressure and diffusion distance at different time $(t=10,20,30,50,70$, and $90 \mathrm{~min})$ were drawn by Matlab R2016b software, which were shown in Figure 5. Based on Figures 3-5, and the derivation process of equation (7), the following can be summarized:

(1) The diffusion distance of superfine cement grout at different time increases as the grouting pressure increases.

(2) When $t<30 \mathrm{~min}$, the grout viscosity increases slowly and the diffusion performance of grouts does not vary much even at different time. However, when $t>30 \mathrm{~min}$, the grout viscosity increases quickly, which exerts a much larger impact on diffusion performance. As the time $t$ increases, the grouting pressure needed to reach the same diffusion distance increases correspondingly. The time-varying characteristic of grout is noticeably influential to its diffusion performance.

(3) Superfine cement grout has an excellent rheological property during pumpable time, and its diffusion performance is less influenced by rheological parameters. However, once pumpable time is over, the grout viscosity increases, whereas its fluidity declines due to the rise in diffusion resistance. Accordingly, it is advisable that the grout should be used immediately when it is made so as to make full use of its pumpable time.

(4) The time-varying characteristics of power-law superfine cement grout can be represented by initial viscosity coefficient $c_{0}$, viscosity rheological coefficient $k$, and rheological index $n$. It can be regulated effectively by adjusting the amount of additive (nano- $\mathrm{SiO}_{2}$ and polycarboxylate superplasticizer).

(5) In actual engineering design, comprehensive consideration should be given to the permeability parameters of the grouted rock like effective permeability $K_{\mathrm{e}}$, porosity $\varnothing$, and time-varying rheological parameters like $c_{0}, k$, and $n$. On this basis, grouting pressure and diffusion time should be calculated reasonably to achieve effective diffusion. Grouting diffusion time should in no way be lengthened blindly.

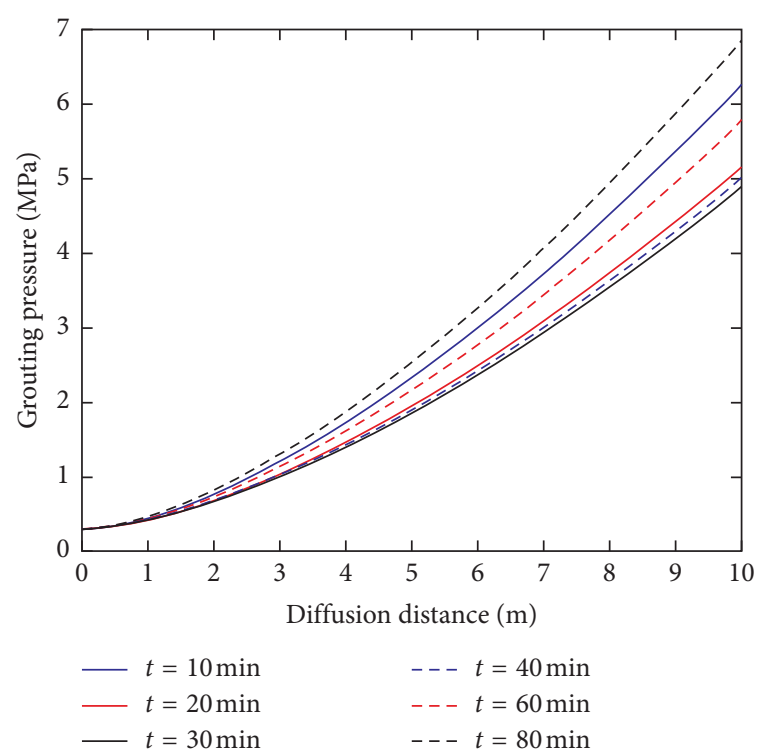

Figure 5: Curves of relation between grouting pressure and diffusion distance.

(6) In the actual grouting project in the wind oxidation zone of Gubei Coal Mine, the diffusion radius is designed at $10 \mathrm{~m}$, and the grout should be diffused within 30 minutes. The calculated grouting pressure should be 6.2 MPa, but given that field grouting is to be influenced by many other factors and the calculated value is smaller than necessary, the grouting pressure is designed to be $6.5 \mathrm{MPa}$.

\section{Superfine Cement Grouting Reinforcement Scheme}

\subsection{Grouting Engineering Design}

4.1.1. Drilling Layout. The grouting reinforcement scheme for 13116 working face is as follows: to arrange seven groups of drill holes along the coal wall inward from the open-off cut; to arrange eight groups of drill holes along the rib of belt haulage roadway close to the working face; to set a $20 \mathrm{~m}$ long interval between the groups; to set the distance to the roof as $0.2 \mathrm{~m}$; and to arrange the final position of grouting hole in the middle of wind oxidation zone. The schematic diagram of drilling layout is shown in Figure 6. For the seven groups of drill holes in the open-off cut, each group has two drill holes at an interval of $1 \mathrm{~m}$. The depths of the drill holes and the angles between the drill hole and horizontal plane are $26.9 \mathrm{~m}$ and $68.2^{\circ}, 39.1 \mathrm{~m}$ and $39.81^{\circ}$, respectively, as is shown in Figure 6(a). For the eight groups of drill holes along the rib of belt haulage roadway, each group has four drill holes at an interval of 


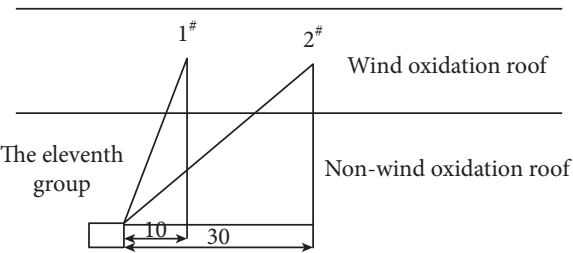

(a)

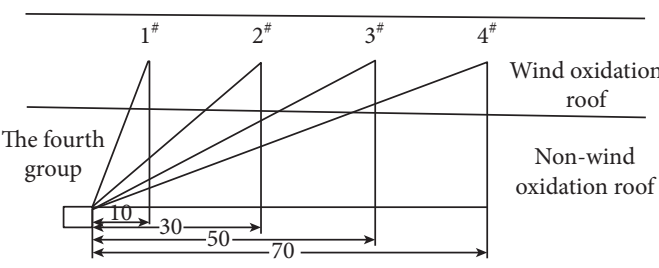

(b)

Figure 6: Schematic diagram of drilling layout. (a) Drilling in the open-off cut. (b) Drilling in belt haulage roadway.

$1 \mathrm{~m}$. The depths of the drill holes and the angles between the drill hole and horizontal plane are $26.9 \mathrm{~m}$ and $68.2^{\circ}$, $39.1 \mathrm{~m}$ and $39.81^{\circ}, 56.2 \mathrm{~m}$, and $26.57^{\circ}, 74.7 \mathrm{~m}$ and $20.38^{\circ}$, respectively, as is shown in Figure 6(b).

4.1.2. Grouting Pipe in the Drill Hole. For each drill hole, a $4 \mathrm{~m}$ long casing pipe was used for hole sealing at first; then, three grouting pipes $(\Phi 13 \mathrm{~mm})$ numbered as $1^{\#}, 2^{\#}$, and $3^{\#}$ according to their length were placed within each drill hole. Grouting pipe $1^{\#}$ was $4 \mathrm{~m}$ long; grouting pipe $2^{\#}$ was long enough to reach the bottom of roof wind oxidation zone with a $2 \mathrm{~m}$ long pouring pipe left in the end; grouting pipe $3^{\#}$ reached up to the final position of drill holes (the middle part of wind oxidation zone) with a pouring pipe left. The schematic diagram of drill grouting pipe arrangement in grouting hole is shown in Figure 7.

The actual grouting order is as follows: to grout grouting pipe $1^{\#}$ first until the slurry returns from grouting pipe $2^{\#}$, then stop the grouting operation in grouting pipe $1^{\#}$ and starting grouting to $2^{\#}$ until it is full; after solidifying for 24 hours, start high-pressure grouting to grouting pipe $3^{\#}$.

\subsection{Construction Technique and Safety Measures for Grouting.} The actual grouting order is as follows:

(1) ZBY-16/22 grout injector was used for grouting; a pneumatic mixer was used to prepare grout; orifice connectors $(\Phi 25 \sim \Phi 19 \mathrm{~mm})$ and high-pressure grouting pipe $(\Phi 25 \mathrm{~mm} / 32 \mathrm{MPa})$ were also needed in the operation process. The grout must be stirred evenly, and a filter screen should be placed at the grout outlet to prevent impurities from being sucked in the grouting pipe.

(2) Two wind-water joint clearing sprayers covering the whole section were placed within the range of $10 \sim 20 \mathrm{~m}$ along the air return side to ensure the normal operation of grouting.

(3) To reinforce the roadway. The broken bolts and cables in the open-off cut and belt conveyor crossheading should be replaced or reinforced. The caved roof in belt haulage roadway should be solidified with cement backboards and reinforced by two sets of canopies. Canopies should be built in the upper flat section of hoisting shaft to

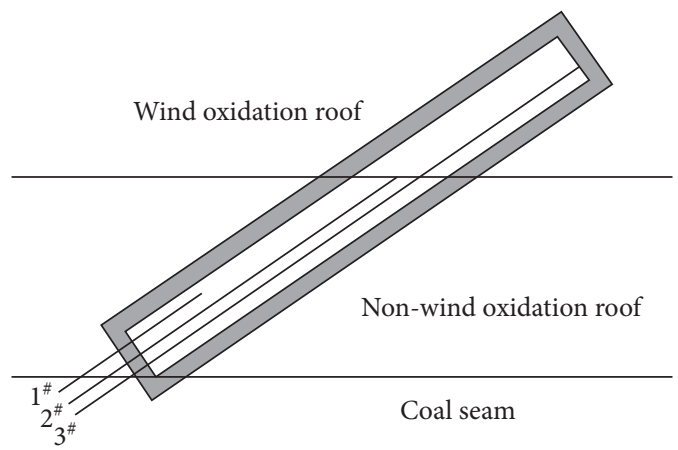

FIGURE 7: Schematic diagram of drill grouting pipe arrangement in grouting hole.

reinforce and support the roof where cables and bolts were seriously damaged. The broken pointed pillars in the original canopy should be replaced.

(4) The extraction team should seal the drill holes with polyurethane and cement when drilling is over. A casing pipe with inner thread should be reserved in the open end to facilitate the later installation of the flange plate.

(5) All the flexible tubes for air and water and grouting pipe should be connected with special U-shaped clamps, and the joints should be fastened with $12^{\#}$ twin wire. In the case of pipeline disassembly, the stop valves should be turned off first before pressure relief. The disassembly work should not begin until the pressure is released.

(6) A piece of $70 \mathrm{~mm}$ thick board plus steel mesh reinforcement should be placed in front the of grout injector to serve as a protective wall no shorter than $1.5 \mathrm{~m}$ to prevent casualties in case of high-pressure grout outbursting.

(7) The grouting pressure is $6.5 \mathrm{MPa}$, and the diffusion radius of each grouting hole is $10 \mathrm{~m}$. The standard for grouting ending is to reach the designed grouting pressure, and the pressure should keep stable at least for 5 minutes.

(8) In the process of grouting, no working staff is allowed to face the drilling hole. Instead, builders should stand by the side while operation. In the process of grouting, if the grout injector and pipeline needs inspecting, it can be done only after the 
pressure is released. Meanwhile, no staff is allowed to stand in front of the pressure relief valve.

(9) In the process of grouting, it is not allowed to grout without pressure gage control or under overpressure. In case of grout leakage, which requires the suspension of grouting operation, the grout injector should be cleaned timely.

4.3. Grouting Effect. ZKXG100 Mine Intrinsically Safe Drillhole Peep instrument was used to observe the grouting effect through the hole drilled in the middle of two groups of drill holes toward wind oxidation zone. Before grouting, drill holes are hard to form due to hole collapse; after grouting, the wind oxidation zone is filled up with superfine cement grout. Accordingly, the drill holes are relatively regular and complete, and the hole wall is quite smooth, which were shown in Figure 8. The visible trace of superfine cement setting indicates that the grout has diffused to the designed area effectively.

During the recovery of 13116 working face, the coal wall and the roof of head face were quite stable without any noticeable ground pressure. The convergence of the two ribs within the range of $20 \mathrm{~m}$ from the exit of belt haulage roadway was relatively remarkable, with the maximum convergence reaching up to $400 \mathrm{~mm}$. To ensure the mining safety of 13116 working face, proper and timely measures have been taken such as adjusting the problematic single props (insufficient stroke, skew, and so on) and strengthening the management of end, corner and section, which have been proved to be effective and satisfactory.

From the end support of the working face, rock pressure monitor is installed every 10 supports. The working resistance of the support is continuously monitored for 50 days. Based on the monitoring data of the front pillar of the hydraulic support, a two-dimensional contour map of the working resistance of the support of the working face is obtained (Figure 9). As shown in Figure 9, there is no abnormal change in roof periodic pressure during the whole mining process, effectively solving the problem of mining under the wind oxidation zone.

\section{Conclusions}

(1) Superfine cement grout with a water-cement ratio of 0.6 is typical power-law slurry consistent with timevarying rheological parameters. It has excellent rheological performance during pumpable time. However, when pumpable time is over, its viscosity increases and its time-varying characteristic exerts a noticeable impact on the diffusion performance. Accordingly, if possible, grouting and diffusion should be completed within the pumpable time.

(2) The effective diffusion of grout in grouted coal and rock mass is critical to successful grouting in wind oxidation zone. To achieve this goal, the effective permeability $\left(K_{\mathrm{e}}\right)$ and porosity $(\varnothing)$ of grouted rock mass should be fully considered. On this basis, the amount of additive (highly dispersive nano- $\mathrm{SiO}_{2}$ and

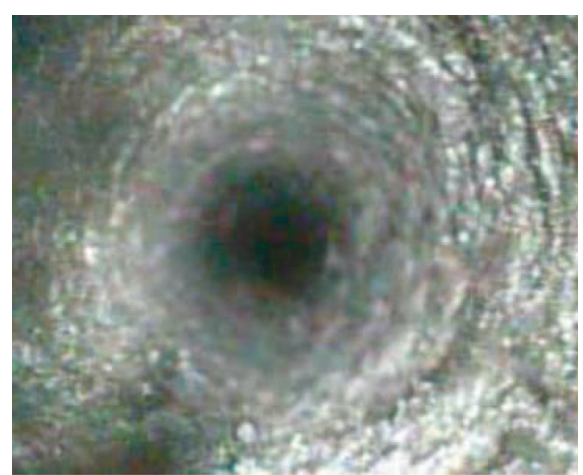

(a)

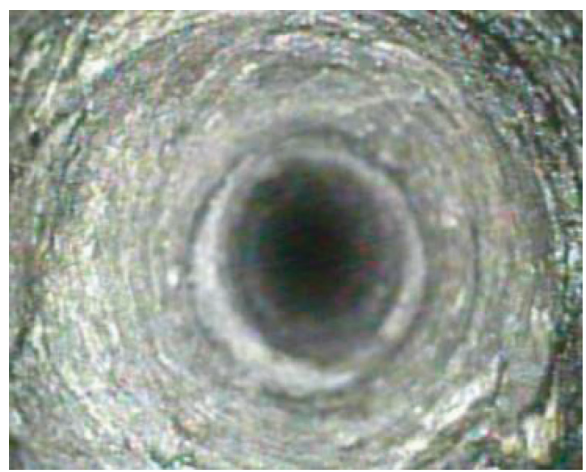

(b)

FIGURE 8: Comparison of peeping holes before and after grouting. (a) Before grouting. (b) After grouting.

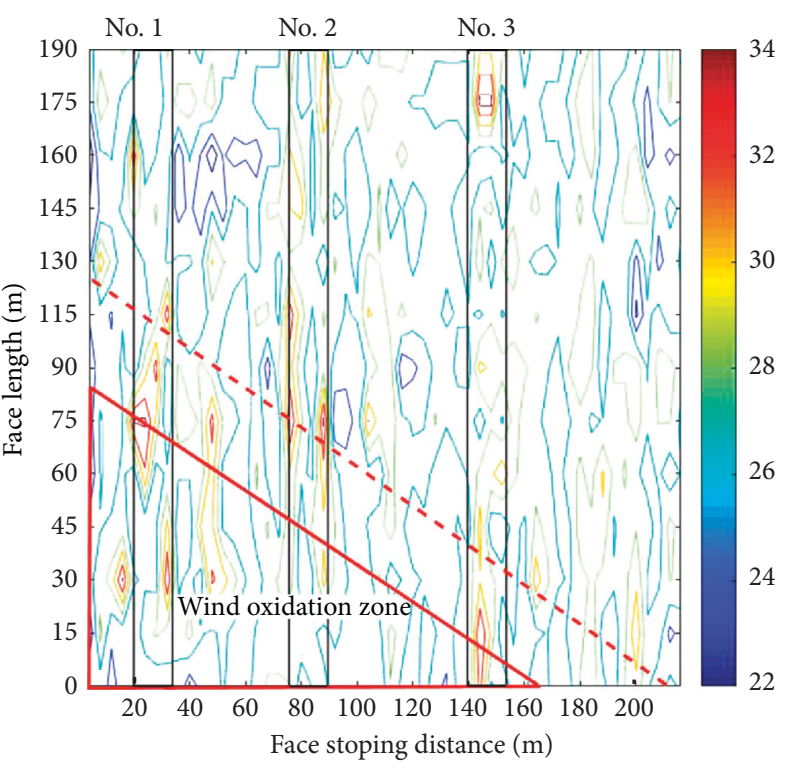

FIGURE 9: Isogram of working resistance of support in working face.

polycarboxylate superplasticizer) can be used to regulate the rheological parameters concerned with the time-varying characteristics of superfine cement grout like initial viscosity coefficient $\left(c_{0}\right)$, timevarying coefficient of viscosity $(k)$, and rheological 
index $(n)$, which then can be substituted into equation (3) to calculate the reasonable grouting pressure and diffusion time. The grouting and diffusion time should be in no way lengthened excessively and blindly.

(3) Grouting wind oxidation zone above the working face with superfine cement grout can reinforce and solidify the roof strata. It can not only reduce the permeability on the one hand but also increase the bearing capacity on the other. Accordingly, it is one of the most effective and convenient methods to improve the structure and strength of overlying strata and surrounding rock in wind oxidation zone.

\section{Data Availability}

The data used to support the findings of this study are available from the corresponding author upon request.

\section{Conflicts of Interest}

The authors declare that there are no conflicts of interest regarding the publication of this paper.

\section{Acknowledgments}

This work was financially supported by the National Natural Science Foundation of China (Grant nos. 51574226 and 51574222), the Natural Science Foundation of the Jiangsu Higher Education Institutions of China (19KJB130004) and the MOHURD Science and Technology Program (2016-R3021 and 2018-K7-004).

\section{References}

[1] M. Tu, H. L. Zhang, C. X. Rong et al., "Research on ground pre-grouting reinforcement and mine pressure characteristics in coal seam adjacent to weathering bedrock," Journal of Mining \& Safety Engineering, vol. 35, no. 6, pp. 1185-1190, 2018.

[2] H. L. Zhang, M. Tu, H. Cheng et al., "Breaking mechanism of overlying strata under thick unconsolidated layers and integrated grouting reinforcement technology for wind oxidation zone," Journal of China Coal Society, vol. 43, no. 8, pp. 2126-2132, 2018.

[3] K. P. Peng, D. Tian, H. Y. Shi et al., "Mechanism analysis of the end face roof collapse on mechanized mining face via wind oxidization zone," Journal of North China Institute of Science and Technology, vol. 10, no. 1, pp. 52-55, 2013.

[4] K. Zhang, "Study on the motion rule of the overlying strata after the whole grouting reinforcement of efflorescent oxygenized belts," Master's thesis, AnHui University of Science and Technology, Huainan, China, 2016.

[5] C. F. Ma, "Numerical simulation on grouting rein-forcement of top and bottom of overwind oxidized zone in fully mechanized mining face," Journal of Shanxi Coal-Mining Administrators College, vol. 29, no. 1, pp. 22-24, 2016.

[6] H. L. Yang and L. Y. Shi, "Study on surrounding rock control technology in fully mechanized mining face via wind oxidation zone," Journal of North China Institute of Science and Technology, vol. 11, no. 1, pp. 33-36, 2014.
[7] D. Tian and H. Y. Shi, "Development and application of high pressure sealing grouting experimental system," Safety in Coal Mines, vol. 46, no. 10, pp. 111-113, 2015.

[8] W. J. Ruan, "Spreading model of grouting in rock mass fissures based on time-dependent behavior of viscosity of cement-based grouts," Chinese Journal of Rock Mechanics and Engineering, vol. 24, no. 15, pp. 2709-2714, 2005.

[9] L. Z. Zhang, Q. S. Zhang, R. T. Liu et al., "Penetration grouting mechanism of quick setting slurry considering spatiotemporal variation of viscosity," Rock and Soil Mechanics, vol. 38, no. 2, pp. 443-452, 2017.

[10] S. C. Li, R. T. Liu, Q. S. Zhang et al., "Research on C-S Slurry diffusion mechanism with time-dependent behavior of viscosity," Chinese Journal of Rock Mechanics and Engineering, vol. 12, no. 12, pp. 2377-2396, 2013.

[11] A. Perrot, T. Lecompte, H. Khelifi, C. Brumaud, J. Hot, and N. Roussel, "Yield stress and bleeding of fresh cement pastes," Cement and Concrete Research, vol. 42, no. 7, pp. 937-944, 2012.

[12] D. Han and R. D. Ferron, "Effect of mixing method on microstructure and rheology of cement paste," Construction and Building Materials, vol. 93, no. 7, pp. 278-288, 2015.

[13] R. M. Ahmed, N. E. Takach, U. M. Khan et al., "Rheology of foamed cement," Cement and Concrete Research, vol. 39, no. 4, pp. 353-361, 2009.

[14] M. Michaux and C. Defosse, "Oil well cement slurries I. Microstructural approach of their rheology," Cement and Concrete Research, vol. 16, no. 1, pp. 23-30, 1986.

[15] M. Zhang, L. K. Chen, Y. J. Xie et al., "Rheology analysis of paste mixed slurry stabilizer," Materials Research Innovations, vol. 19, no. 8, pp. 907-910, 2015.

[16] K. H. Khayat and A. Yahia, "Effect of welan gum-high-range water reducer combinations on rheology of cement grout," ACI Materials Journal, vol. 94, no. 5, pp. 365-372, 1997.

[17] M. Lachemi, K. M. A. Hossain, V. Lambros, P.-C. Nkinamubanzi, and N. Bouzoubaâ, "Performance of new viscosity modifying admixtures in enhancing the rheological properties of cement paste," Cement and Concrete Research, vol. 34, no. 2, pp. 185-193, 2004.

[18] M. Sonebi, "Rheological properties of grouts with viscosity modifying agents as diutan gum and welan gum incorporating pulverised fly ash," Cement and Concrete Research, vol. 36, no. 9, pp. 1609-1618, 2006.

[19] K. H. Khayat, A. Yahia, and M. Sayed, "Effect of supplementary cementitious materials on rheological properties, bleeding, and strength of structural grout," ACI Materials Journal, vol. 105, no. 6, pp. 585-593, 2008.

[20] D. Lowke, "Interparticle forces and rheology of cement based suspension," in Nanotechnology in Construction 3, Springer, Berlin, Germany, 2009.

[21] S. Lu, "Influence of ground mineral admixtures on rheological behavior of cement-based grouting materials," Master's thesis, Harbin Institute of Technology, Harbin, China, 2006.

[22] B. Nikbakhtan and M. Osanloo, "Effect of grout pressure and grout flow on soil physical and mechanical properties in jet grouting operations," International Journal of Rock Mechanics and Mining Sciences, vol. 46, no. 3, pp. 498-505, 2009.

[23] I.-M. Lee, J.-S. Lee, and S.-W. Nam, "Effect of seepage force on tunnel face stability reinforced with multi-step pipe grouting," Tunnelling and Underground Space Technology, vol. 19, no. 6, pp. 551-565, 2004.

[24] W. J. Ruan, "Research on diffusion of grouting and basic properties of grouts," Chinese Journal of Geotechnical Engineering, vol. 27, no. 1, pp. 69-73, 2005. 
[25] Z. Q. Yang, X. D. Niu, K. P. Hou et al., "Columnar diffusion of cement grout with time dependent rheological parameters," Chinese Journal of Rock Mechanics and Engineering, vol. 34, no. 7, pp. 1415-1425, 2015, in Chinese.

[26] National Standard Compilation Group of the People's Republic of China, GB/T50123-1999 Standard for Soil Test Method, China Planning Publishing House, Beijing, China, 1999.

[27] C. Y. Yin, G. M. Feng, Y. Ding et al., "Research on rheological properties of the single super-high-water material slurry," Metal Mine, vol. 6, pp. 41-46, 2017.

[28] Z. C. Chen, "Several problems in cement filling process of geological exploration," Exploration Engineering, vol. 11, no. 2, pp. 13-16, 1981.

[29] Z. C. Chen, "Sulphoaluminate geological exploration cement, a new material for wall protection and leakage stoppage," Geology and Prospecting, vol. 12, no. 3, pp. 64-67, 1981.

[30] G. Z. Dai, Y. M. Sheng, S. J. Li et al., "Experiment analysis on the groutability of PBFC impervious material of waste landfill," Bulletin of the Chinese Ceramic Society, vol. 37, no. 2, pp. 561-566, 2018.

[31] National Standard Compilation Group of the People's Republic of China, GB/T8077-2012 Method for Testing Uniformity of Concrete Admixture, General Administration of Quality Supervision, Inspection and Quarantine of the People's Republic of China, Beijing, China, 2012. 


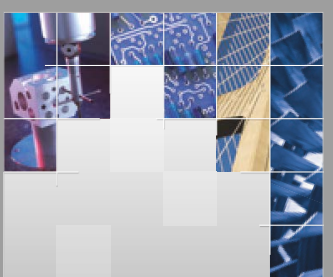

\section{Enfincering}
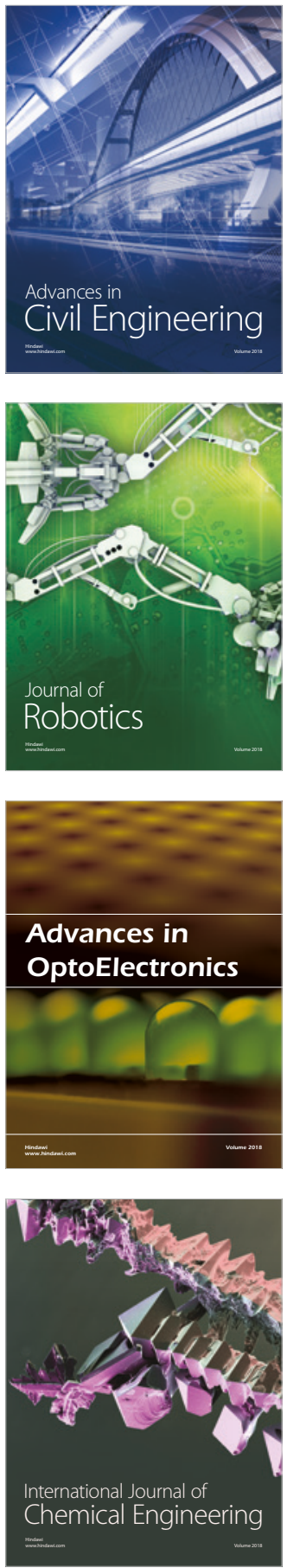

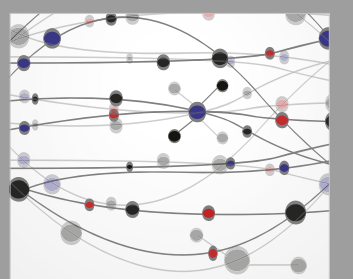

\section{Rotating \\ Machinery}

The Scientific World Journal

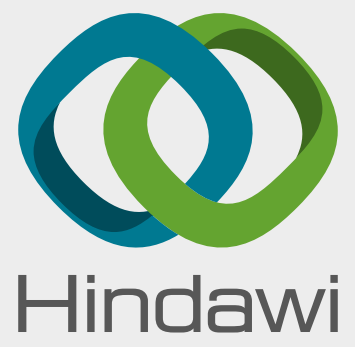

Submit your manuscripts at

www.hindawi.com
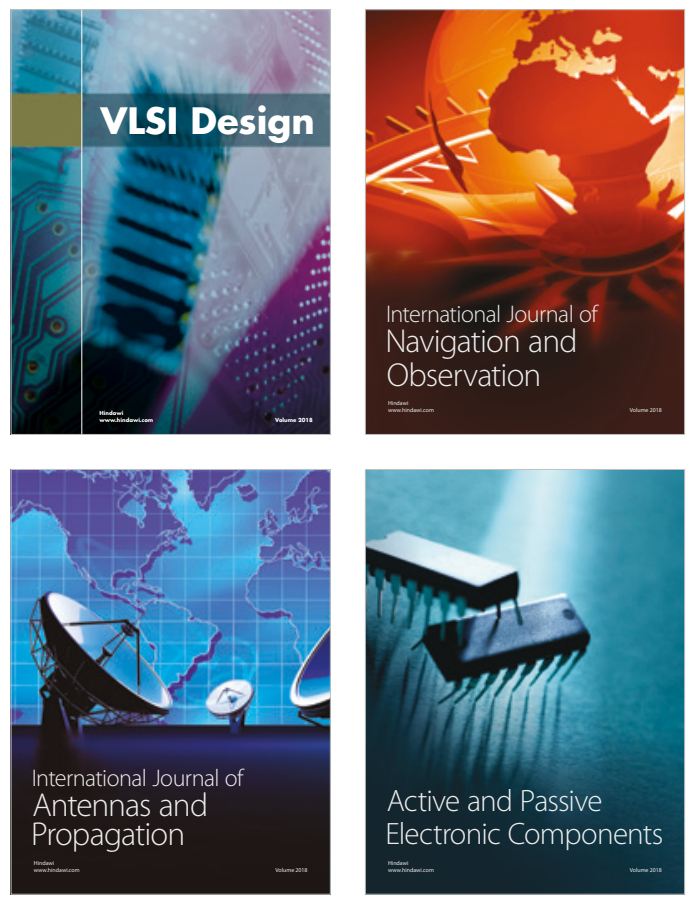
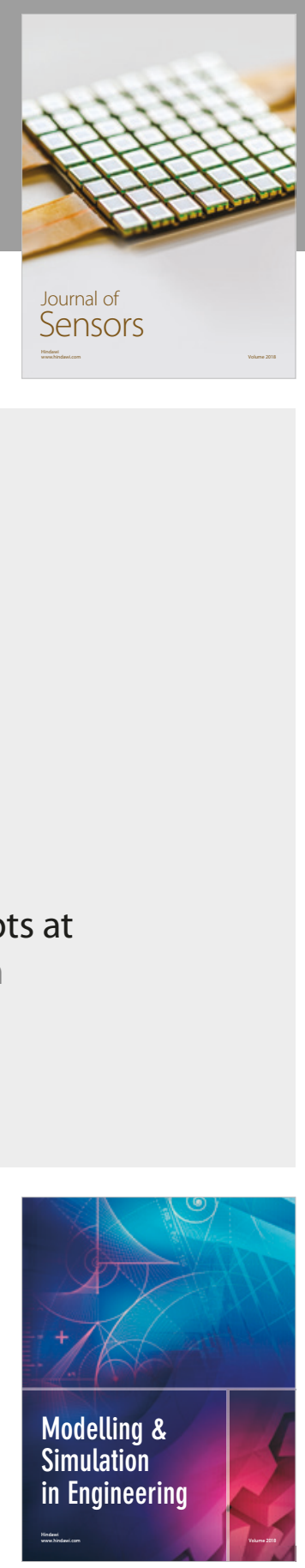

\section{Advances \\ Multimedia}
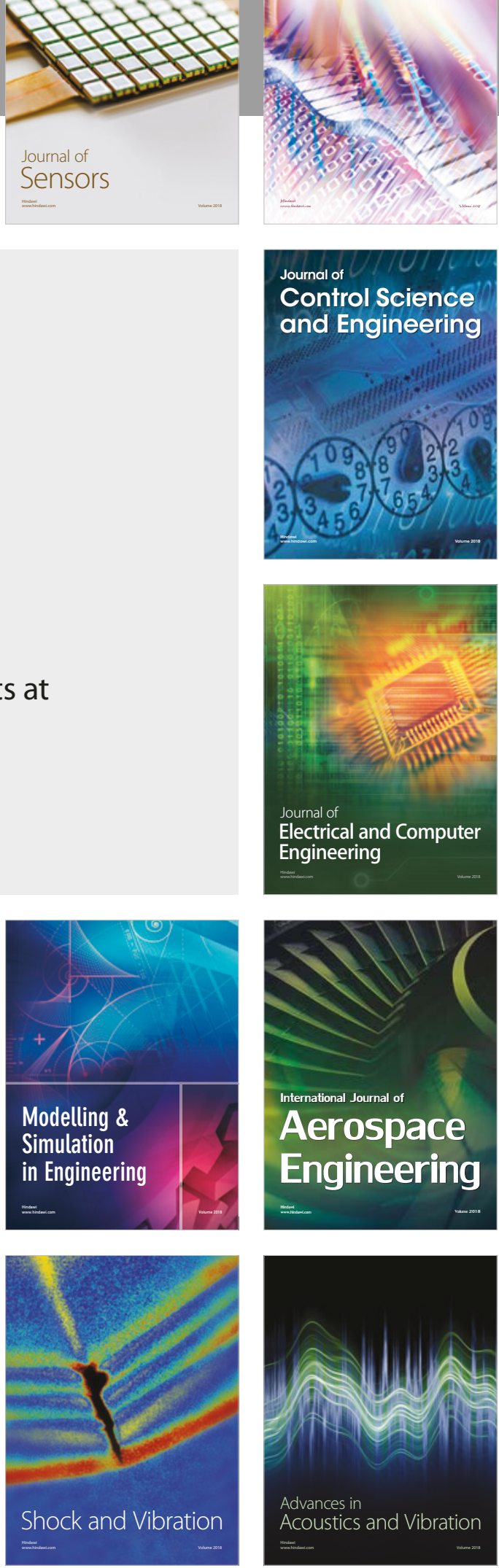